\title{
Paroxysmal hypothermia and hyperhidrosis with exacerbation after COVID-19 Infection
}

\author{
Guillaume Lamotte $^{1} \mathbb{C} \cdot$ Eduardo E. Benarroch $^{1} \cdot$ Elizabeth A. Coon ${ }^{1}$
}

Received: 23 January 2021 / Accepted: 27 January 2021 / Published online: 2 February 2021

(c) Springer-Verlag GmbH Germany, part of Springer Nature 2021

Keywords Shapiro syndrome $\cdot$ COVID-19 $\cdot$ Hypothermia

\section{Dear editors,}

We present the case of a 49-year-old woman with exacerbation of paroxysmal hyperhidrosis and hypothermia after COVID-19 infection.

A 49-year-old woman presented to the autonomic disorder clinic for evaluation of paroxysmal hyperhidrosis and hypothermia. Starting at age 46 , she experienced episodes of hyperhidrosis, most pronounced in the face and upper body, followed by profound hypothermia $\left(32-33^{\circ} \mathrm{C}\right)$ associated with confusion and lethargy. Episodes were triggered by minimal intensity physical activity and heat exposure. Each episodes lasted 3-6 h, and they happened on average once per month. Her medical history was significant for hypertension as well as endometriosis and ovarian cyst treated with total abdominal hysterectomy and bilateral salpingooophorectomy. Neurological examination was unremarkable. Laboratory testing including thyroid and adrenal function tests was unremarkable. Magnetic resonance imaging of the brain was unremarkable, with intact corpus callosum. Standardized autonomic testing revealed normal postganglionic sympathetic sudomotor, cardiovagal, and cardiovascular adrenergic functions. A thermoregulatory sweat test (TST) demonstrated lower extremity anhidrosis. The results of the TST and quantitative sudomotor axon reflex test were consistent with preganglionic (central) sudomotor dysfunction (Fig. 1). The patient was diagnosed with Shapiro syndrome variant. She started clonidine extendedrelease $0.1 \mathrm{mg}$ daily by mouth with complete resolution of the symptoms. She was able to resume her daily activities without any limitations.

Guillaume Lamotte

Lamotte.Guillaume@mayo.edu

1 Department of Neurology, Mayo Clinic, 200 1st Street SW, Rochester, MN 55905, USA
Six months later she presented with severe fatigue, cough, muscle ache, joint pain, and fever $\left(39.5^{\circ} \mathrm{C}\right)$. Severe acute respiratory syndrome coronavirus 2 (SARS-CoV-2) was positive using real-time polymerase chain reaction from a nasopharyngeal swab collection. The patient was diagnosed with mild COVID-19 infection. Outpatient treatment was conservative and symptoms resolved slowly over 3 weeks. During the acute phase of the COVID-19 infection, periods of hypothermia alternated with fever for 4 days. After the recovery phase, however, episodic hyperhidrosis and hypothermia persisted without fever despite the use of clonidine. The patient experienced several episodes of profound hypothermia, all triggered by minimal exertion (e.g., cleaning the house). The dose of clonidine extended-release was increased to $0.1 \mathrm{mg}$ twice daily, which led to complete resolution of the symptoms.

Shapiro syndrome is a rare disorder defined clinically by recurrent hyperhidrosis and hypothermia and radiologically by agenesis of the corpus callosum [1]. The variant form refers to the phenotypic Shapiro syndrome without the corpus callosum abnormality [2]. The pathophysiology of Shapiro syndrome remains poorly understood and may be in part related to hypothalamic dysfunction without structural lesion [1]. Pharmacotherapy with different mechanisms of action may provide symptomatic benefit, suggesting involvement of various neurotransmitters [3].

SARS-CoV-2 is a novel coronavirus responsible for COVID-19. Acute infection has been associated with various neurological manifestations possibly related to endothelial inflammation, cytokine storm, immune reaction, or direct invasion of the central nervous system by the virus [4]. Persistence of symptoms after the acute phase of the infection is not rare; many long-haul COVID patients experience orthostatic intolerance, tachycardia, brain fog, persistent fatigue, and subjective change in body temperature [5]. 
Fig. 1 Thermoregulatory sweat test (TST) and quantitative sudomotor axon reflex test (QSART) in a patient with Shapiro syndrome variant. Absence of sweating on TST in the context of normal QSART responses indicates preganglionic (central) sudomotor dysfunction

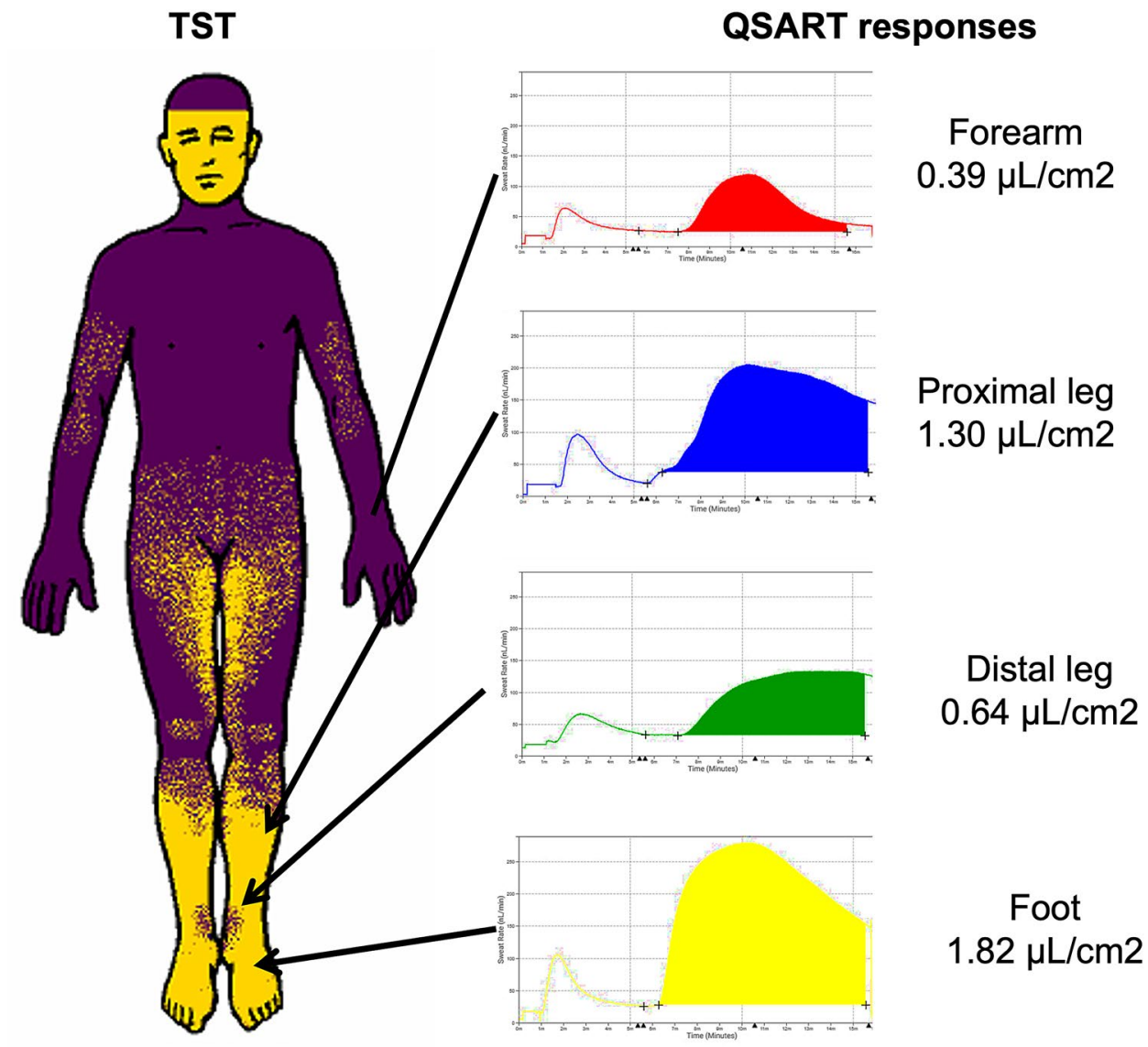

The hypothalamus is part of the central autonomic network and plays a key role in thermoregulation. In Shapiro syndrome, episodic hyperhidrosis is thought to be related to paroxysmal central sympathetic dysregulation, which could explain the benefit of sympatholytic agents such as clonidine [2]. There is evidence that SARS-CoV-2 can lead to hypothalamic dysfunction via direct invasion of the virus and/or reactive inflammation with the olfactory tracts as a port of central nervous system entry [6]. The hypothalamus and associated regions have been shown to express the angiotensin-converting enzyme 2 and transmembrane proteinase, serine 2 , which mediate SARSCoV-2 cellular entry [6]. It can be hypothesized that in the present case, COVID-19 infection, either directly or via cytokine-induced release of prostaglandin E2 from endothelial cells acting via paracrine mechanisms, could have exacerbated dysfunction in the medial preoptic area containing warm-sensitive neurons, triggering excessive sweating and thus hypothermia, exacerbating the preexisting symptoms of variant Shapiro syndrome [7].

Further studies are needed to investigate the possible involvement of the hypothalamus and central autonomic network in COVID-19 infection.
Funding Supported by NIH (P01NS44233, U54NS065736, K23NS075141, R01 FD004789, R01 NS092625), Cure MSA Foundation, and Mayo Funds.

\section{Compliance with ethical standards}

Conflict of interest The corresponding author affirms that none of the authors has a conflict of interest.

\section{References}

1. Shapiro WR, Williams GH, Plum F (1969) Spontaneous recurrent hypothermia accompanying agenesis of the corpus callosum. Brain 92(2):423-436. https://doi.org/10.1093/brain/92.2.423

2. Tambasco N, Belcastro V, Prontera P, Nigro P, Donti E, Rossi A, Calabresi P (2014) Shapiro's syndrome: defining the clinical spectrum of the spontaneous paroxysmal hypothermia syndrome. Eur J Paediatr Neurol 18(4):453-457. https://doi.org/10.1016/j. ejpn.2014.02.001

3. Blondin NA (2014) Diagnosis and management of periodic hypothermia. Neurol Clin Pract 4(1):26-33. https://doi.org/10.1212/01. CPJ.0000437350.47610.3a

4. Meinhardt J, Radke J, Dittmayer C, Franz J, Thomas C, Mothes R, Laue M, Schneider J, Brünink S, Greuel S, Lehmann M, Hassan O, Aschman T, Schumann E, Chua RL, Conrad C, Eils R, Stenzel W, Windgassen M, Rößler L, Goebel HH, Gelderblom HR, Martin H, Nitsche A, Schulz-Schaeffer WJ, Hakroush S, Winkler MS, Tampe B, Scheibe F, Körtvélyessy P, Reinhold D, 
Siegmund B, Kühl AA, Elezkurtaj S, Horst D, Oesterhelweg L, Tsokos M, Ingold-Heppner B, Stadelmann C, Drosten C, Corman VM, Radbruch H, Heppner FL (2020) Olfactory transmucosal SARS-CoV-2 invasion as a port of central nervous system entry in individuals with COVID-19. Nat Neurosci. https://doi. org/10.1038/s41593-020-00758-5

5. Nath A (2020) Long-Haul COVID. Neurology 95(13):559-560. https://doi.org/10.1212/wnl.0000000000010640

6. Nampoothiri S, Sauve F, Ternier G, Fernandois D, Coelho C, Imbernon M, Deligia E, Perbet R, Florent V,
Baroncini M, Pasquier F, Trottein F, Maurage C-A, Mattot V, Giacobini P, Rasika S, Prevot V (2020) The hypothalamus as a hub for SARS-CoV-2 brain infection and pathogenesis. bioRxiv:2020.2006.2008.139329. https://doi. org/10.1101/2020.06.08.139329

7. Saper CB, Romanovsky AA, Scammell TE (2012) Neural circuitry engaged by prostaglandins during the sickness syndrome. Nat Neurosci 15(8):1088-1095. https://doi.org/10.1038/nn.3159 